\title{
Proposal of Formal and Non-Formal Education for New Generation Digital Learning Demand in Engineering
}

\author{
Tamara Pigozne \\ University of Latvia \\ Riga, Latvia \\ tamara.pigozne@lu.lv
}

\author{
Arturs Medveckis \\ Liepaja University \\ Liepaja, Latvia \\ arturs.medveckis@liepu.lv
}

\begin{abstract}
Millennial generation, starting from twelveyear-olds up to adolescents, is one of the most complicated generational cohorts; its ecosystem, beyond of formal and non-formal education boundaries, is more diverse than for any other previous generation.

Digital learners prefer a digital learning environment, as the advantage of digital learning is the control over time, place, way and pace, enabling you to impersonate as an educational institution, applying smart personal network which consists of 3 domains: applied smart technologies; reflexive pedagogy for the digital century [1]; learning environment [2], thus without any confrontation of formal and non-formal education, but rather with consolidation of resources to promote engineering development of formal environment at school, higher educational establishments and informal activities - projects, scientists' night events, open days, interest-related education programmes, etc.

Goal of the research is to analyse the proposal of formal and non-formal education for the new generation digital learning demand and identify the examples of good practice in engineering, based on the identified digital leaning criteria obtained as a result of theoretical analysis.

In the design research of cross-sectional study 323 respondents took part: 226 representatives of formal education and 97 representatives of non-formal education.

In the research the quantitative and qualitative data collection (questionnaires, case analysis) and processing (nonparametric software in SPSS environment and content analysis) methods have been applied.

Results of Mann-Whitney U-test to two independent samples confirm statistically significant differences depending on the respondents' profile: representatives of non-formal education tend to value

Higher such digital learning criteria as situational
\end{abstract}

and authentic, whereas representatives of formal education value higher interactive digital learning on demand, which is related to application of different media platforms $(p \leq 0.05)$.

The research analyses the examples of good practice in case studies in engineering.

Engineering can be geared towards fundamental research, but in the pupils' educational process the innovative solutions of technical sciences with a perspective of practical applicability arouse a greater interest. Learning efficiency and acquisition of new knowledge are successful if learning is linked to research work in higher educational establishments and transfer of findings in the education system in close collaboration with representatives of economic sectors and businesses.

Keywords - Millennial generation, formal, non-formal education, digital learning, engineering.

\section{INTRODUCTION}

The paradigm or conceptual framework shift, that has taken place in this new millennium, has brought changes in economics, culture, education and other sectors. Due to the social and economic conditions and shrinking of the labour market, the entering of the adult age has become more complex and requires a longer and more complicated "prologue of adult life". As the result it has created a new developmental stage (age of 17-18 years) called young or emerging adulthood, which is not universal, but a cultural construct characterized by changes of personality in cognitive, emotional, physical and social sphere [3].

Nowadays, the predicted forecasts that in the new era the marketplace will be replaced by the network, the property rights replaced by access, which will impact also the concept of personality as the idea of an autonomous personality existing in a particular space will be replaced with an idea of a changing personality, which is dependent on the others and exists is time [4] - have become a reality. Although the future is associated 
with "an equation where all its variables are undefined" [5], digital learning is one of the answers to this challenge and the opportunity to overcome it [2] with the condition that in the learning process the focus is not on the use of technologies as an end in itself, but on the effective, efficient [6] and meaningful [7] use of technologies, providing educational sustainability, because "technology is only a tool" [8] and its meaningful use depends on the pedagogue.

In order to generate interest into engineering professions among the youth, a mobile Techno-buss financed by the Mechanical Engineering and Metalworking Association operates in Latvia, which is equipped with engineering devices for demonstration, where one can get acquainted with real examples of technology application, demonstrating a digitally programmable metalwork or making a part programmed with a 3D printer.

In order to prevent the overproduction of humanitarian and social workers and lack of specialists in the engineering field, broad reforms are being implemented in formal education in Latvia.

While reforming the educational content for the implementation of the competence-based approach in Latvia, in the basic education phase engineering has been included in the offer of the field of technology, where pupils will obtain some experience "to create useful engineering solutions for themselves and others - strengthen such engineering problem-solving skills as constructing and projecting, material strength and compatibility analysis, ability to make judgements on the need for a specific solution and its impact on the society and environment, observe work safety requirements and intensify the development of such general or transversal skills as problemsolving and creativity" [9]. In its turn, in the comprehensive secondary education succession is provided implementing educational programmes with a higher proportion of subjects in mathematics, natural sciences and technology.

During the last decade in order to raise capacity and consolidate resources for a qualitative teaching of the STEM (science, technology, engineering and mathematics) field subjects, providing the link with the content of the higher education study programme content and motivating pupils for a conscious career choice in the engineering/ technology area, a tendency can be noticed among higher educational institutions to establish secondary schools with a more profound acquisition of engineering (Riga Technical University) and technologies (Rezekne Academy of Technologies).

In the Education Law both formal education has be defined as the "system which comprises in itself levels of basic education, secondary education and higher education, whose acquisition is certified by a stated-recognized educational or professional qualification document" [10] and non-formal education as "educational activities organized outside formal education in compliance with one's interests and demand" [10], thus affirming the place and role of non-formal education in the interest and motivation creation about engineering and learning achievement improvement in hard sciences in general.

The objective of education is "to produce an unbridled hunger for "new" knowledge and "new" skills and competences. The place where all this can be found and all this can be learned is cyberspace. Present continuously here and everywhere, accessible to everyone” [5].

\section{MATERIALS AND METHODS}

In the teaching process, cooperating with learners, teachers have a challenge to build a trustful relationship with the millennial generation, which is characterized by scepticism and the slogan: "Do not Teach Me, Let Me Learn" [11].

Although it is not possible to draw direct conclusions about the impact of digital technologies on students' learning [12] also the research studies reveal contradicting results: from one side they highlight the close relationship of millennials with information, their media literacy and the ability to use technologies for accessing the information [13], but they also claim that millennials "are not capable of dealing with modern technologies in a way, which is often ascribed to them (i.e., that they can navigate the world for effective and efficient learning and knowledge construction)" [6].

Millennial generation is characterized by:

- Independence, investing effort and succeeding;

- Diversity, characterized by openness to everyone and to everything;

- Engagement, supporting environmental and civil rights initiatives or activities;

- Knowledge management, quickly filtering the amount of information and selecting what is valuable;

- $\quad$ Pragmatism - when choosing career;

- $\quad$ Personal brands, presenting one’s identity;

- Collaboration, practicing it in the physical and virtual environment [13].

Prefer a digital learning environment, millennial generation cope with the growing use of mobile devices and social media networks for academic purposes, but also their need for constant and instantaneous feedback on their learning process [14], [15]. Their need for success and immediate recognition is satisfied with such tools as gamification, a public leaderboard, social learning and quick feedback mechanisms [11].

The applied smart technologies (equipment, gadgets, necessary software, artificial intellectual technologies), digital pedagogy or reflexive pedagogy for the digital century [1] provide support for the smart technology application in the learning process; the learning environment "brings together the learner's academic portfolio and supporting learning network" [2], creates the smart personal net in digital learning environment for the millennial generation, obtaining control over time, space, manner and pace.

As a result of theoretical analysis, the digital learning criteria and indicators were identified:

- Interactive (attractive content and materials, which motivate the engagement and creative use of social media);

- Learner-centred (emphasis on educator's support during the learning, and student's responsibility for their own learning and modelling);

- Situational (use of technologies associated with genuine learning and internal motivation);

- Collaboration (learning as a social activity);

- On-demand (use of different media platforms to access the content);

- Authentic (active and meaningful activity, which is based on a real-life learning models) [13]. 
The research questions are:

- What is the relevance of the digital learning offer to Millennial generation demand in formal and nonformal education?

- $\quad$ Are there any differences in the assessment of digital learning criteria depending on the respondents' profile?

- Is there correlation between the digital learning criteria?

The research method: exploratory research applying a quantitative and qualitative research approach. An online survey was administered by applying a questionnaire containing a 5point Likert scale: 1 = strongly disagree, 2 = disagree, 3 = somehow agree, 4 = agree and 5 = strongly agree).

In the design research of cross-sectional study 323 respondents took part: 226 representatives of formal education (111 pupils and 68 students, 30 teachers and and 17 academic staff) and 97 representatives of non-formal education (38 pupils and 26 students, 20 teachers and and 13 academic staff) from different education institutions of Latvia.

Cronbach's alpha coefficient assessing reliability of the test shows a good internal consistency $(\alpha=83)$.

Kolmogorov-Smirnov Test results on non-compliance of empirical division with the norm ( $\mathrm{p}=.000$ ) determined the use of nonparametric methods for acquisition of secondary data.

Empirical data processing methods using SPSS software were applied to provide quantitative data processing methods:

- Mann-Whitney-U Test for determination of statistical significance of differences between two independent samples;

- Kendall correlation analysis for determination of relationships between indicators.

\section{RESULTS AND DISCUSSION}

The results of the Mann-Whitney U Test show that there are statistically significant differences in the demand and supply of digital learning depending on the profile of the respondents (See Table 1).

Representatives of formal education have rated interactive and on-demand learning higher than respondents of non-formal education. The offer of various media platforms in formal education for the acquisition of engineering content is sufficient, binding and appropriate for the target audience, which motivates educators to use it in a creative way in the millennium generation teaching process. Formal education at school has got the characteristics of a hierarchical system, characterized by the results to be achieved at each level of education and by expanding the amount of knowledge to be acquired in the time dimension. However, with higher education, the students' choice to improve in the academic or professional direction is more distinct.

On the other hand, representatives of non-formal education tend to appreciate situational and authentic learning more highly. As non-formal education is mostly related to interests, as well as to intrinsic motivation to acquire new knowledge, improve their skills in order to raise competitiveness, then it has got certain advantages in specific knowledge acquisition in a relatively short time, but formal education is often constrained by institutional bureaucratic conditions. The format of non-formal education is more flexible, offering the opportunity to achieve results in a shorter period of time.

Table I Results of the Mann-Whitney U Test: Significant Differences Formal and Non-formal Education Representatives

\begin{tabular}{|c|c|c|c|}
\hline 焉 & $\begin{array}{c}\text { Results of } \\
\text { Mann-Whitney } \\
\text { U Test }\end{array}$ & $\begin{array}{c}\text { Higher } \\
\text { evaluated by }\end{array}$ & $\begin{array}{c}\text { Lower } \\
\text { evaluated by }\end{array}$ \\
\hline 莡 & $\begin{array}{c}U=12085.000 \\
\mathbf{p}=\mathbf{. 0 0 0}\end{array}$ & $\begin{array}{c}\text { Formal } \\
\text { education } \\
\text { representatives } \\
\text { Mean Rank } \\
\text { 309,36 }\end{array}$ & $\begin{array}{c}\text { Non-formal } \\
\text { education } \\
\text { representatives } \\
\text { Mean Rank } \\
\text { 230,33 }\end{array}$ \\
\hline 岂 & $\begin{array}{c}U=10826,000 \\
p>.05\end{array}$ & $\begin{array}{c}\text { Formal } \\
\text { education } \\
\text { representatives } \\
\text { Mean Rank } \\
296.80\end{array}$ & $\begin{array}{c}\text { Non-formal } \\
\text { education } \\
\text { representatives } \\
\text { Mean Rank } \\
272.84\end{array}$ \\
\hline 栉 & $\begin{array}{c}U=12111.000 \\
\mathbf{p}=\mathbf{. 0 0 0}\end{array}$ & $\begin{array}{c}\text { Non-formal } \\
\text { education } \\
\text { representatives } \\
\text { Mean Rank } \\
299.48\end{array}$ & $\begin{array}{c}\text { Formal } \\
\text { education } \\
\text { representatives } \\
\text { Mean Rank } \\
232.90\end{array}$ \\
\hline 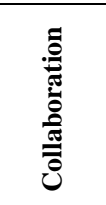 & $\begin{array}{c}\mathrm{U}=11068,000 \\
\mathrm{p}>.05\end{array}$ & $\begin{array}{l}\text { Non-formal } \\
\text { education } \\
\text { representatives; } \\
\text { Mean Rank } \\
270,73\end{array}$ & $\begin{array}{c}\text { Formal } \\
\text { education } \\
\text { representatives } \\
\text { Mean Rank } \\
\text { 247,39 }\end{array}$ \\
\hline כ & $\begin{array}{c}\mathrm{U}=12602.000 \\
\mathbf{p}=\mathbf{. 0 0 1}\end{array}$ & $\begin{array}{c}\text { Formal } \\
\text { education } \\
\text { representatives } \\
\text { Mean Rank } \\
290.42\end{array}$ & $\begin{array}{c}\text { Non-formal } \\
\text { education } \\
\text { representatives } \\
\text { Mean Rank } \\
244.12\end{array}$ \\
\hline 葛 & $\begin{array}{c}\mathrm{U}=12555,500 \\
\mathbf{p}=\mathbf{. 0 0 0}\end{array}$ & $\begin{array}{l}\text { Non-formal } \\
\text { education } \\
\text { representatives } \\
\text { Mean Rank } \\
\text { 281,99 }\end{array}$ & $\begin{array}{c}\text { Formal } \\
\text { education } \\
\text { representatives } \\
\text { Mean Rank } \\
\text { 225,04 }\end{array}$ \\
\hline
\end{tabular}

In its turn, there are no statistically significant differences in the assessment of student-cantered learning and cooperation educator's support is essential in both formal and non-formal education. The possibilities of using different media platforms motivate them to use them creatively in formal and non-formal education; the educator's support in learning promotes cooperation; an active and purposeful activity in real life situations enhances the intrinsic motivation.

Teachers and academic staff tend to evaluate higher such criteria as interactive exercises, situational learning, learning ondemand and authentic learning in comparison to the pupils and students $(\mathrm{p}=.000)$. Pupils and students' responses, on the other hand, indicate that there is a great demand for more diverse and interesting use of media, including age-appropriate learning materials, as well as for modelling and problem-solving in reallife situations and in a particular context.

Students have ranked higher the interactive and situational learning, as well as learning on-demand than pupils ( $p=.009$ ). But pupils have a tendency to evaluate higher the cooperation and authentic learning. In the context of learner-centred learning, pupils have emphasized the teacher's support, but students - their 
own responsibility; modelling was equally important for both groups of respondents.

Teachers assessed higher the learning and cooperation in class than the academic staff, which tend to evaluate higher the authentic learning, teaching on-demand and interactive learning $(\mathrm{p}=.031)$.

As a result of Kendall correlation analysis, a statistically significant correlation between the digital learning criteria has been found (see Table 2).

Table II Kendall Correlation Analysis: Statistically Significant Correlation between the Digital Learning Criteria

\begin{tabular}{|c|c|c|c|c|c|}
\hline 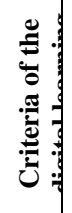 & 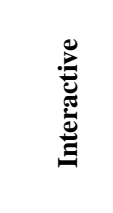 & 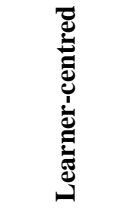 & 尝 & 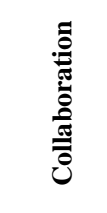 & 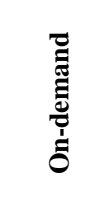 \\
\hline & $\begin{array}{l}r=.75 \\
p<.001 .\end{array}$ & & & & \\
\hline & $\begin{array}{l}r=.81, \\
p<.001 .\end{array}$ & $\begin{array}{l}=.77 \\
p<.001 .\end{array}$ & & & \\
\hline & $\begin{array}{l}r=.63, \\
p<.001 .\end{array}$ & $\begin{array}{l}r=.79, \\
p<.001 .\end{array}$ & $\begin{array}{l}r=.82, \\
p<.001 .\end{array}$ & & \\
\hline & $\begin{array}{l}r=.70, \\
p<.001 .\end{array}$ & $\begin{array}{l}r=.67, \\
p<.001 .\end{array}$ & $\begin{array}{l}r=.71, \\
p<.001 .\end{array}$ & $\begin{array}{l}r=.72, \\
p<.001 .\end{array}$ & \\
\hline & $\begin{array}{l}r=.69 \\
p<.001 .\end{array}$ & $\begin{array}{l}r=.63 \\
p<.001 .\end{array}$ & $\begin{array}{l}r=.68, \\
p<.001 .\end{array}$ & $\begin{array}{l}r=.64, \\
p<.001 .\end{array}$ & $\begin{aligned} r & =.61, \\
p & <.001 .\end{aligned}$ \\
\hline
\end{tabular}

An active and purposeful activity, which is based on the real-world learning models, as it is directed towards certain problem-solving which the contemporary youth encounter in their daily life and in the surrounding social environment, motivates creative application of different technologies and media, promotes collaboration and responsibility for their learning.

Application of technologies, using smart devices, initially is most often related to application of different media resources offered by the entertainment industry. As smart technologies play an increasingly important role in everyday life, car building, logistics and elsewhere, the high level of digitalization sets requirements not only to be able to manage the smart technologies as users of the product on offer, but be the multiplicators of the new technology development and knowledge themselves. In order to be able to implement knowledge transfer, cooperation between specialists from different fields of activity is necessary, where a representative of each industry is responsible for the quality of the performance of their assigned duties. For instance, in the building industry with a high export capacity, specialists of engineering industry, designers, marketing specialists, logistics and transport specialists are needed, who are familiar not only with the smart technologies of their industry, but due to the digital learning in formal and non-formal education have developed transversal skills to be able to work in team, to cooperate and be motivated, be responsible for their learning which ensures competitiveness of the company and the whole industry in the global market.

Application of various media platforms in engineering acquisition promotes learning as a social activity, raises intrinsic motivation and responsibility, as well as application of social media.

Getting involved in a dialogue with the representatives of similar interests, skills and knowledge are already being transferred in the informal environment in order to acquire the skills and abilities that ensure inclusion in the social environment where digital skills are essential. The knowledge acquired in the informal environment, as a result of a skilful pedagogical activity, can be adapted in the acquisition of engineering sciences in teamwork which is similar to the acquired type of socialization provided by the accumulated experience in the informal environment. In group work, for instance, during some project development in the learners' environment the intrinsic motivation is raised to prove one's individual skills, but common goals develop responsibility. For example, during the Covid-19 pandemic, the youth invent and offer more rational solutions to solve the tasks formulated by teachers/ lecturers, using the possibilities offered by social media which had already been applied in the informal knowledge circulation.

Monitoring of factors influencing environmental habitats in open water reservoirs can be performed according to a certain algorithm, using human workforce, but floating data acquisition laboratories can also be used, which have been given a task to obtain, process different data and transmit them from the monitored environment at certain coordinates through global positioning systems to the research institution. Such an idea has been implemented at Faculty of Science and Engineering of Liepaja University, implementing the project "Application of GPS Technologies for Environmental Monitoring.” To implement the idea, knowledge in biochemistry, environmental sciences, physics is necessary, one has to be familiar with radio engineering, knowledge and practical skills as of constructors are required.

Learning as a social activity with the teacher's support offers opportunities for authentic learning, modelling, engaging content and the use of materials.

Teaching staff of higher educational institutions, cooperating with school teachers, engaging students and pupils in a unified educational process, can transfer the acquired knowledge and experience in engineering sciences through modern media both in such public events as Science Nights and in the digital environment, preserving the evidence of the achieved outcomes, which encourage other pupils and students to collaborate, experiment, accumulated new knowledge and apply it in a creative way to solve practical tasks. Socially significant future-orientated educational measures, such as projects supported by Liepaja Municipality, implemented by the teaching staff of Liepaja University in work with talented pupils, who acquire programming elements, developing digitally 
controlled mechanical models, create multi-media optical installations etc., can be considered as successful. Spatial visualization in architecture and urban planning has become a widespread technique on a daily basis, which is being adapted by new researchers as an analogous model in order to implement their creative intentions in the offer of new computer games or also to develop different software related to robotics.

Situational studies are associated with student-centered and interactive learning.

Distance learning methods, which in comprehensive schools was a sporadic phenomenon, during the global pandemic has become as a norm. The process of the students' scientific research work development and their work presentation online is a clear example. Due to the unexpected situation both the teachers and learners' creative abilities have been unlocked. The situation of pupils' SRW is characterized by both the topics related to the analysis of the consequences of the pandemic, which affected the condition of culture, economic life, social welfare, and mental health. At the same time social skills and technologies have been acquired in order to document the empirical data obtained as a result of surveys and interviews and to ensure appropriate data protection. Thanks to engineering achievements, video interviews, electronic signature or computerized data processing have become reality. Also, measurements of sports and physiological condition of the body can be measured with electronic smart devices, which promote physical activities and their monitoring, but the corresponding data analysis, based on a certain methodology, opens an opportunity for scientific studies in medicine, sports pedagogy, etc.

The teacher's support encourages pupils to apply social media in a creative way.

The open public space of social media for most of the youth is an approbated digital environment which ensures high publicity to a wide range of users in a very short time, but the uploaded information remains for a long time. Adherence to socially responsible ethical principles is important. Positive examples are related to the acquisition of natural sciences by posting videos depicting the processes happening in nature, integrating quizzes or other game elements in order to acquire new knowledge. For instance, on the FB platform the teacher, a specialist of Liepaja environmental sciences, frequently uses filmed materials on different natural phenomena, on ecosystem's functioning etc., which is not only an authentic study resource, but also an encouraging way for pupils to carry out observations, research and exchange of thoughts remotely. In prototyping laboratories engineering students in cooperation with scientists and industry specialists develop both environmentally friendly packaging packages and automatically controlled devices for the disinfection of premises, etc. innovations.

Application of an exciting content and materials, which motivate participation and creative use of social media in interactive learning, influence the application and cooperation of different media platforms in a positive way, as well as raise pupils' motivation and responsibility to get involved in an active and purposeful activity. The creative industries, exhibitions of virtual artwork, applying engineering solutions - illuminating environmental objects, transferring the images to be projected to various formats, reviving frozen photos, etc. open opportunities for the commercialization of inventions to the technology, art, advertising market. Outstanding examples of engineering and their achievement demonstration are the creative solutions of New Media Studies of Liepaja University, using sound waves, turning the oscillations created by them into artwork. The knowledge and skills acquired through millennium generation's digital learning are an essential prerequisite and important resource for the integration of smart technologies in various essential areas of life; they are especially significant for the offer of creative technological solutions in relation to engineering, as well as the creation and transfer of knowledge, mutual communication, creation, preservation and transfer of new cultural products.

\section{CONCLUSIONS}

The research results confirmed the ideas suggested by other studies - the internet as a virtual learning environment offers authentic materials, meaningful interactions [16] and socialization opportunities [17], and "the digital-material tools employed represent a valuable resource for students' learning process" [18] in formal and informal education environment of engineering.

At different stages of education formal and non-formal education create the synergy effect during the engineering acquisition period which ensures sustainable development of engineering sciences and technologies, promotes the increase of competitiveness potential and facilitates the development of economic sectors.

Currently in Latvia, the digital learning offerings partly correspond to the pupils' demand, but in the process of education content reform and implementing the competence-based approach, the following transversal skills are developed: digital and critical thinking, problem-solving, creativity, entrepreneurial ability, self-guided learning, cooperation, and civic participation. Digital learning is a powerful resource in engineering for improving of all of them in accordance with the demand of the labour market.

\section{REFERENCES}

[1] M. Kalantzis and B. Cope, Introduction: The Digital LearnerTowards a Reflexive Pedagogy. . In M. Montebello (Ed.), Handbook of Research on Digital Learning (pp. 18-31). IGI Global. 2020

[2] Montebello, M. (2020). I Am the Institution: A Personal Learning Environment. In M. Montebello (Ed.), Handbook of Research on Digital Learning (pp. 291-301). IGI Global.

[3] J.E. Côté, “The dangerous myth of emerging adulthood: An evidence-based critique of a flawed developmental theory”, Applied Developmental Science, vol. 18(4), pp.177-188, 2014.

[4] J. Rifkin, The Age Of Access: The New Culture of Hypercapitalism, Where All of Life is a Paid-For Experience, Putnam Publishing Group, 2000.

[5] E. Duda and K. Dziurzyński, "Digital competence learning in secondary adult education in Finland and Poland", International Journal of Pedagogy Innovation and New Technologies, vol. 6(2), pp.22-32, 2019.

[6] P.A. Kirschner and P. Bruyckere, "The myths of the digital native and the multitasker”, Teaching and Teacher Education, vol. 67, 135-142, 2017.

[7] L. Daniela, A. Visvizi, C. Gutiérrez-Braojos., and M.D. Lytras, "Sustainable Higher Education and Technology-Enhanced Learning (TEL)”, Sustainability, vol. 10(11), 3883, 2019. 
[8] R. Birzina and T. Pigozne, “Technology as a Tool in STEM Teaching and Learning” in Rural Development, Education, Personality, Jelgava, 08.-09.05.2020, pp. 219-227, 2020.

[9] Engineering class 7, 2020. [Online]. Available: https://mape.skola2030.lv/resources/164 [Accessed March 15, 2021].

[10] Education Law, 1999. [Online]. Available: https://ikumi.lv/ta/en/en/id/50759 [Accessed March 13, 2021].

[11] A. Jain, "Don't Teach Me, Let Me Learn! Millennial Learning”, Indore Management Journal vol. 8(1), pp. 64-71, 2016.

[12] V. Harju, A. Koskinen, and L. Pehkonen, “An exploration of longitudinal studies of digital learning”, Education Research, vol. 61(4), 388-407, 2019.

[13] G.L. Witt and D.E. Baird, The Gen Z Frequency: How Brands Tune In and Build Credibility, United Kingdom, 2018.
[14] A. Hanif, F.Q. Jamal, and M. Imran, "Extending the Technology Acceptance Model for Use of e-Learning Systems by Digital Learners”, EEE Access, vol. 6(1), pp. 73395-73404, 2018.

[15] P. Faustino and D. Simões, "The Contribution of the Technology Acceptance Model for an Active Teaching and Learning Process in Higher Education: A Bibliometric Analysis” in M. Montebello (Ed.), Handbook of Research on Digital Learning, IGI Global, pp. 242-261, 2020

[16] C.A. Bohinski, C.A. “Click here for L2 learning!” in Pixel (Ed.) Conference proceedings: ICT for Language Learning, Padova, Italy: Libreriauniversitaria.it, pp.144-148, 2014.

[17] C.A. Lenkaitis, "Valuing technology in the L2 classroom: Student and teacher perceptions, preferences, and digital identity" in M. Montebello (Ed.), Handbook of Research on Digital Learning, IGI Global, pp. 173-189, 2020.

[18] C. Damsa, "Learning with digital technologies in higher education”, Journal of Educational, Sciences and Psychology, vol. 9(71), pp. 5-9, 2019. 